\title{
La reivindicación del catolicismo militante en el antimaquiavelismo ibérico del siglo XVI. E1 De nobilitate christiana (1542) de Jerónimo de Osorio
}

\section{The assertion of militant catholicism in the Iberian anti-Machiavellianism of the sixteenth century. De Nobilitate Christiana (1542) by Jeronimo de Osorio}

Mario Prades Vilar*

Universidad Andrés Bello

\section{Resumen}

Este artículo examina el De nobilitate (1542) de Jerónimo Osorio como una obra clave de creación y transmisión del repertorio argumental y del imaginario antimaquiavélico propio de la cultura ibérica del siglo XVI. Este imaginario se

* Doctor en Historia por las universidades de Pisa y Barcelona. La investigación que condujo a la elaboración de este artículo fue posible gracias a una beca de estudios de doctorado concedida por el Ministero dell'Istruzione, dell'Università e della Ricerca italiano en 2006; así como a una beca de investigación otorgada en 2009 por la Scuola Normale Superiore di Pisa para estudiantes no italianos. Quisiera agradecer a los profesores Helena Puigdomènech, Adriano Prosperi, Michele Olivari, Juan Manuel Forte y Enrico De Angelis su confianza, apoyo y supervisión durante aquellos años.

Contacto: mario.prades@unab.cl. 
centra, sobre todo, en la refutación del pasaje de Discursos II, 2 en el que Maquiavelo niega al cristianismo capacidad para ejercer los valores militares. Frente a esta tesis, autores como Juan Ginés de Sepúlveda, Osorio o Pedro de Ribadeneyra reivindican un catolicismo militante y guerrero, que encuentra plena vigencia en el contexto del Imperio español y sus ansias expansionistas.

Palabras clave: Jerónimo de Osorio, Nicolás Maquiavelo, Pedro de Ribadeneyra, Ginés de Sepúlveda, antimaquiavelismo

\section{Abstract}

This article examines the De nobilitate (1542) by Jerónimo de Osorio as a key piece for the creation and dissemination of the argumental repertoir of the sixteenth century anti-machiavellism in the Iberian culture. This imaginary focuses mainly in refuting the passage from Discourses II, 2 in which Machiavelli denies Christianity any ability to exercise military values. Contrary to this thesis, authors such as Juan Ginés de Sepúlveda, Osorio or Pedro de Ribadeneyra claim a militant and warrior Catholicism, which thrived fully in the context of the Spanish empire and its expansionist ambitions.

Keywords: Jerónimo de Osorio, Pedro de Ribadeneyra, Niccolo Machiavelli, Ginés de Sepúlveda, antimachiavellism 


\section{La crítica a Maquiavelo en la cultura ibérica del siglo XVI}

La obra política de Nicolás Maquiavelo (1469-1527) ha suscitado controversia y escándalo prácticamente desde su misma aparición. Consecuentemente, son numerosos los estudios dedicados exclusivamente a sus críticos, hasta tal punto que el maquiavelismo y el antimaquiavelismo constituyen categorías propias dentro del ámbito de las investigaciones en torno a la figura y el pensamiento de Maquiavelo (Procacci 1965; 1995). De hecho, las primeras críticas político-religiosas dirigidas contra su obra aparecieron durante la primera mitad del siglo XVI. Muestra de ello son la Apologia ad Carolum Quintum (1535) del cardenal inglés Reginald Pole; o el mismo tratado De nobilitate (1542) de Jerónimo de Osorio, objeto de este estudio. Les siguieron obras como el Discours... contre Nicolas Machiavel Florentin (1576), de Innocent Gentillet, el Iudicium... de Nicolao Machiavello (1592), de Possevino, o el Tratado del príncipe cristiano (1595), de Pedro de Ribadeneyra, sobre quien volveremos. Son obras muy diversas en su intención y en el programa político y moral que proponen, como no podía ser de otro modo si tenemos en cuenta la biografía de sus autores: si Pole es un religioso erasmista, Gentillet es un jurista hugonote, mientras que Possevino y Ribadeneyra son jesuitas, compañía con la que simpatizó también Osorio. Estos dos últimos se inscriben, de hecho, en el ámbito de lo que podríamos llamar antimaquiavelismo contrarreformista. Este consiste, siguiendo a Robert Bireley, en una corriente de pensamiento político que busca refutar las "escandalosas" ideas de Maquiavelo (la separación, por ejemplo, entre moral y política) desde su propio terreno de juego, esto es, atendiendo a las necesidades que la práctica del poder impone (violencia, guerra, mentira) sin, por ello, condenar el ejercicio de la política a la impiedad. Su objetivo, por tanto, es el de proponer una razón de Estado que combine la eficacia 
política con una preceptiva subordinación a los principios cristianos, que aúne "la utilidad y el bien" (1990: 239). Según Bireley, dos serían los fundadores de esta corriente de pensamiento político: el italiano Giovanni Botero y el flamenco Justo Lipsio, con sus respectivas obras Della Ragion di Stato (1589) y Politicorum sive civilis doctrinae libri sex (1586). Ribadeneyra formaría parte de esta corriente junto a Diego Saavedra Fajardo, Carlo Scribani y Adam Contzen. A pesar de las diferencias entre estos cuatro autores, Bireley destaca la unidad proveniente de su filiación jesuita $\mathrm{y}$, por tanto, la influencia que el tomismo tiene en su pensamiento político (1990: 234-242). Sin negar esta lectura, el presente trabajo propone un enfoque diverso, que orienta la interpretación de parte del antimaquiavelismo dentro de unas coordenadas ideológicas y geográficas precisas: las de la cultura políticoreligiosa ibérica del siglo XVI.

Sydney Anglo, en su estudio sobre la recepción de Maquiavelo durante el siglo XVI, afirma que el caso español "is a subject which has been much studied, although there is not really much to study" (2005: 175). Sin embargo, publicaciones posteriores sobre el antimaquiavelismo en la península ibérica parecen desmentir esta apreciación del estudioso británico ${ }^{1}$. Tal vez llevado por esta consideración, Anglo olvida

1 Por citar dos publicaciones recientes, puede consultarse The Reception of Machiavelli in Early Modern Spain (2014), de Keith D. Howard, y el volumen Maquiavelo y España. Maquiavelismo y antimaquiavelismo en la cultura española de los siglos XVI y XVII (2008), editado por Juan Manuel Forte y Pablo López Álvarez, donde se encuentran referencias a textos clásicos como los de José Antonio Maravall, José Antonio Fernández-Santamaría o Helena Puigdomènech. Cabe destacar que Howard se opone a las tesis de Fernández Santamaría y Bireley, para quienes la influencia de Maquiavelo habría sido escasa en España (coincidiendo, por tanto, con Anglo). Estos se apoyan en que "la perspectiva de los antimaquiavélicos fue diametralmente opuesta a la de Maquiavelo", ante lo cual Howard sostiene 
mencionar en su trabajo al filósofo cordobés Juan Ginés de Sepúlveda, quien bien pudiera ser el primer crítico de $\mathrm{Ma}-$ quiavelo fuera de Italia - disputaría este honor con Reginald Pole. Así, como bien intuyó Alessandro Prosperi en su momento (1979: 509) y confirmó Alejandro Coroleu posteriormente (1992: 266), Sepúlveda dedica parte de su diálogo Democrates primus (Roma 1535) a refutar las ideas de Maquiavelo, a quien seguramente leyó durante su estancia en Roma al servicio del papa Clemente VII -Julio de Medici, quien auspició la redacción de la Historia de Florencia maquiaveliana.

El diálogo de Sepúlveda trata, explícitamente, "de convenientia disciplinae militaris cum christiana religione" y crítica dos tesis importantes en la Europa del siglo XVI: la primera, ligada al pacifismo erasmista, afirma que el cristiano no debe hacer la guerra; la segunda, de raíz maquiaveliana, sostiene que el cristiano no puede hacer la guerra. Centrándonos en la segunda, la idea de Maquiavelo, tal como la expresa en sus Discorsi sopra la prima Deca di Tito Livio (1531), es que el cristianismo, al ser una religión centrada en la humildad y el perdón, no es capaz de forjar en el individuo valores cívicos y militares. Por este motivo, los cristianos no son capaces de defender las repúblicas de quienes las atacan. Frente a esta tesis, Sepúlveda acude al repertorio argumental y tópico al alcance de su notable erudición -desde fuentes veterotestamentarias hasta doctrinas aristotélicas, de gran influencia

que este juicio se basa en una lectura superficial del florentino, que no tiene en cuenta "la complejidad y diversidad de interpretaciones de los textos" maquiavelianos. Por tanto, ambos autores habrían caído en la trampa de dar por bueno el juicio de los antimaquiavélicos sobre Maquiavelo en tanto interpretación indiscutible de su obra, por una parte; y en tanto opinión sincera de los mismos críticos del florentino, por otra, lo que les da una apariencia de impermeabilidad, respecto al pensamiento de Maquiavelo, que no por estar construida hábilmente debemos dar por cierta (2014: 10-11). 
en su obra- para reivindicar un cristianismo compatible con la milicia y dar forma, así, a la imagen de un soldado cristiano que, lejos de rechazar la violencia y el conflicto, es el más resuelto y aguerrido a la hora de luchar a las órdenes de un príncipe cristiano por defender su religión. La crítica a este pasaje de Maquiavelo la encontramos, tras Sepúlveda, en otros dos autores importantes dentro de la cultura religiosa ibérica de ese siglo: Jerónimo de Osorio, quien alude al florentino en su De nobilitate christiana (1542), y Pedro de Ribadeneyra, quien retoma los argumentos de ambos en una obra de mayor amplitud, dedicada explícitamente a refutar las tesis de Maquiavelo: el Tratado del príncipe cristiano (1595) ${ }^{2}$.

A diferencia de otros críticos de Maquiavelo del siglo XVI, como Reginald Pole -quien criticaría la justificación de la simulación religiosa por parte del príncipe-, Sepúlveda, Osorio y Ribadeneyra rechazan, en primer lugar, la tesis de la incapacidad del cristiano para la vida militar. Un análisis de las obras citadas permite rastrear argumentos, autoridades, ejemplos, lecturas y presupuestos teóricos comunes a los tres autores, a lo largo de un periodo de 70 años (tiempo que media entre la publicación del Democrates y la aparición del Tratado del principe cristiano). Este hecho supone un excelente indicio de lo que realmente interesa a los pensadores antimaquiavélicos peninsulares del siglo XVI y permite establecer una diferencia fundamental respecto a autores de otros ámbitos geográficos y culturales, como Italia, Inglaterra o Francia. Como ha señalado Adriano Prosperi (1994), una respuesta a Maquiavelo que pone en primer plano y justifica

2 El título completo de la obra es: Tratado de la religión y virtudes que debe tener el principe christiano, para gobernar y conservar sus estados, contra lo que Nicolás Maquiavelo y los políticos deste tiempo enseñan. Se estampa en la imprenta de Pedro de Madrigal en Madrid en 1595, a costa del mercader de libros Juan de Montoya. Para este artículo citaremos la edición moderna a cargo de don Vicente de la Fuente (1910). 
el aspecto bélico y agresivo del catolicismo es característica de la sociedad castellana del siglo XVI, en la medida en que esta se funda sobre el ideal de la ampliación de la Reconquista y la extensión de la cruzada en todo el globo. La refutación del pasaje de Discursos II, 2 sobre la incapacidad del cristiano para la guerra resulta, por tanto, propia de la teología política hispana de la época, tal como también ha señalado Henry Mechoulan (1994, 1997: 87).

Este artículo se propone examinar el De nobilitate de Jerónimo Osorio como un lugar de creación y transmisión del repertorio argumental y del imaginario antimaquiavélico propio de la cultura castellana del siglo XVI. Interesa, por tanto, iluminar las conexiones con el Democrates e identificar los lugares comunes (prestados o de nueva creación) que se retomarán, con una distancia de 53 años, en el Tratado de Ribadeneyra. El objetivo, de este modo, es dar cuenta del lugar prominente del texto de Osorio dentro una corriente de crítica a Maquiavelo propia de parte del pensamiento político peninsular de la época. Para ello, resulta indispensable, en primer lugar, prestar atención a su trayectoria vital y las circunstancias políticas de la composición de la obra. En segundo lugar, resulta necesario identificar brevemente el pasaje maquiaveliano que será objeto de su crítica.

\section{Sobre Jerónimo de Osorio}

Conocido como "el Cicerón portugués", Jerónimo Osorio de Fonseca (1506-1580) fue un humanista de fama internacional (para estas notas biográficas seguimos a Bell 1928, Tejada 1945 y Díaz 1998). Nacido en Lisboa, a la edad de trece años estudia leyes en Salamanca. En 1525 marcha a París a estudiar filosofía, donde traba amistad con el grupo de los primeros jesuitas seguidores de Ignacio de Loyola, especialmente Pedro Fabro, con el que le ligaría una estrecha rela- 
ción. Posteriormente ingresa en el Colegio de San Clemente en Bolonia, tal como hiciera Ginés de Sepúlveda en 1515. En él obtuvo, como Sepúlveda, un profundo conocimiento de Aristóteles, si bien sus preferencias filosóficas siempre se inclinaron por Platón. Durante su estancia en Italia, Osorio conoció a importantes miembros de la Iglesia, como los cardenales Pietro Bembo, Jacopo Sadoleto y Gasparo Contarini; además del futuro obispo de Tarragona, Antonio Agustín, quien protagoniza su diálogo De Gloria (1552), en el que también alaba a sus otros tres amigos (Bigalli 1990).

En 1537, el rey João III lo llama a la Universidad de Coímbra para ejercer de profesor de Escrituras y, tres años después, es nombrado tutor del príncipe Luiz, futuro prior de Crato y padre del don Antonio que contestaría a Felipe II sus derechos al trono portugués en $1580^{3}$. Tras la muerte del príncipe Luiz en 1555, su hermano, el cardenal Henrique, se convierte en el nuevo protector de Osorio. En 1560 es nombrado archidiácono de Évora y en 1564 obispo de Silves. Más adelante mantiene una estrecha relación con el joven rey Sebastián, a quien intenta disuadir inútilmente de su famosa expedición a Alcazarquivir. Tras la desaparición del monarca asiste a la coronación de su protector, el cardenal don Henrique, en 1578. Este muere a los dos años, igual que Osorio poco después, no sin antes haber tomado partido rotundo en la cuestión sucesoria a favor del monarca castellano Felipe II frente al ya mencionado don Antonio, perteneciente a una casa que le había protegido y a la que había servido.

Osorio fue autor de numerosas obras teológicas, históricas y políticas, además mantuvo una constante relación epistolar con algunas de las personalidades más eminentes de las letras europeas. Benito Arias Montano fue amigo personal del por-

3 Según Tejada (1945: 343), si bien Anglo matiza que fue secretario del príncipe Luiz y tutor de su hijo (2005: 144). 
tugués, igual que Roger Ascham en Inglaterra. Su fama llegó a oídos de Montaigne, quien en el capítulo 40 del primer libro de sus Ensayos califica a Osorio de "non mesprisable historien latin de nos siècles" (1838: 131). A pesar de haber escrito crónicas como el De rebus Emmanuelis Regis Lusitaniae invictissimi virtute et auspicio gentis $(1576)^{4}$, historia del reinado del rey Manuel encargada por el cardenal Henrique, Osorio es, principalmente, humanista y teólogo. Como Ribadeneyra y Sepúlveda, escribe sobre la educación del príncipe cristiano en su De regis institutione et disciplina (1571); entra en polémica con Lutero en su De Justitia Caelesti, que dedica al cardenal Pole en una carta de 1557 (Bell 1928: 537); y se enfrenta también al reformista inglés Walter Haddon en su opúsculo In Gualterium Haddonum magistrum (1567). También escribe diálogos de estilo humanista como el ya citado De Gloria, entre muchos otros. Tras su muerte, su sobrino homónimo compila toda la producción de Osorio en una Opera omnia (1592) en cuatro volúmenes dedicada a Felipe II, en la que da cuenta de la mucha fama que todos sus trabajos dieron al obispo de Silves en vida (Castro 1994: 452).

Anglo, quien dedica un capítulo de su obra al antimaquiavelismo de Osorio, destaca tres temas clave para entender la fama y la reputación de la cual gozó el humanista lusitano: su habilidad como latinista e historiador; su carta a la reina Isabel de Inglaterra, en la que le ruega que vuelva a la religión católica, seguida de su controversia con Haddon; y su temprano ataque a Maquiavelo en el De nobilitate (2005: 144). Trataré este último aspecto, pero antes resulta necesario revisar, aunque sea brevemente, el famoso pasaje maquiaveliano que será objeto del ataque de Osorio.

4 Obra que, al parecer, Montaigne poseía en su biblioteca (Bjaï 2013:656). 


\section{Maquiavelo y la incapacidad militar del cristiano}

Los Discorsi sopra la prima Deca di Tito Livio fueron impresos por primera vez en 1531, cuatro años después de la muerte de Maquiavelo, y conocieron desde ese momento varias reediciones y traducciones hasta su inclusión en el Índice inquisitorial romano en $1559^{5}$. Es posible, por tanto, que Osorio hubiera leído una de las ediciones italianas, pues él mismo habla de los libros en los que Maquiavelo escribió la historia de su ciudad "y muchas cuestiones relativas a la República", si bien la afirmación es un tanto ambigua, tal como veremos.

En el segundo capítulo del segundo libro de los Discursos, el canciller florentino se ocupa de "qué pueblos tuvieron los romanos que combatir, y cuán tenazmente defendieron aquellos su independencia". Para tal propósito, Maquiavelo no deja de notar que las antiguas repúblicas defendían su libertad con mucha mayor virulencia y decisión que las modernas, por lo que se pregunta "de dónde pudiera nacer que en los tiempos antiguos los pueblos fueran más amantes de la libertad que en los modernos". El motivo radica en la diversidad religiosa: "porque habiéndonos mostrado nuestra religión la verdad y el verdadero camino, nos hace tener en menor estima el honor del mundo. Sin embargo, los Gentiles, estimándolo mucho, y habiendo puesto en él el sumo

5 El título completo de esa primera edición es: Discorsi di Niccolò Machiavelli cittadino, et segretario fiorentino sopra la prima Deca di Tito Livio a' Zanobi Buondelmonti, et a' Cosimo Rucellai, y fue impresa por Antonio Blado en Roma y Bernardo di Giunta en Florencia. Vale la pena recordar que en 1552 la imprenta de Guillermo de Millis, en Medina del Campo, publicó una traducción española por obra de un no bien identificado Juan Lorenzo Ottevanti, con aprobación de Carlos V. Hay que tener en cuenta que, a pesar del Índice romano, las obras de Maquiavelo no serían prohibidas en España hasta la publicación del Índice inquisitorial del cardenal Quiroga en 1583 (Puigdomènech 1988: 97). 
bien, eran más feroces en sus actos". Ejemplo de esto lo constituyen, para el florentino, los sacrificios, magníficos y violentos en el caso de los antiguos, humildes y delicados en el caso de los modernos.

Además, Maquiavelo advierte otro motivo para esta dramática diferencia: la religión antigua "no beatificaba más que hombres llenos de gloria mundana, como capitanes de ejércitos y príncipes de repúblicas. Nuestra religión ha beatificado más los hombres humildes y contemplativos que los activos", situando además el sumo bien en la humildad y "el desprecio de las cosas humanas". Este modo de vivir, concluye Maquiavelo, "parece que haya debilitado el mundo, convirtiéndolo en presa de los hombres malvados, los cuales seguramente pueden manejarlo a su antojo". "La mayor parte de los hombres -continúa-piensa más en soportar sus golpes que en vengarlos", por lo que, "parece afeminado el mundo y desarmado el cielo". El florentino termina su argumentación matizando que esta debilidad se debe, en realidad, a "la vileza los hombres, que han interpretado nuestra religión según el ocio, y no según la virtud”. Esto último,

6 Traduzco de la edición de Giunta de los Discorsi: "Pensando addunque dove possa nascere, che in quelli tempi antichi i Popoli fossero più amanti della libertà, che in questi; Credo nasca da quella medesima cagione, che fa hora gli uomini manco forti, la quale credo sia la diversità della educazione nostra dalla antica, fondata dalla diversità della Religione nostro dalla antica. Per che avendoci la nostra religione mostro la verità, et la vera via ci fa stimare meno l'honore del mondo. Onde i Gentili stimandolo assai, et avendo posto in quello il sommo bene, erano nelle actioni loro più feroci". "La religione antica oltre di questo non beatificava se non gli uomini pieni di mondana gloria, come erano Capitani di eserciti, et Principi di Repubbliche. La nostra religione ha beatificato più gli huomini humili, et contemplativi, che gli attivi. Ha di poi posto il sommo bene, nella humiltà, abietione, nel dispregio delle cose humane". "Et se la religione nostra richiede, che tu habbi in te forteza, vuole che tu sia atto à patire, più che à fare una cosa forte. Questo modo di vivere 
como se verá, Osorio lo interpreta como un mero expediente exculpatorio ante el alcance religioso y político de las afirmaciones de Maquiavelo.

\section{La crítica a Discursos II, 2 en De nobilitate}

Osorio publica su primera obra, De nobilitate, en Lisboa en 1542, cuando cuenta con treinta y seis años de edad, si bien la compuso durante la década anterior ${ }^{7}$. Los dos primeros

addunque pare, che habbi renduto il mondo debole, et datolo in preda a gli huomini scelerati, i quali sicuramente lo possono maneggiare. Veggendo come l'università de gli huomini per andare in Paradiso, pensa più à sopportare le sue battiture, che à vendicarle, et ben che e' paia che si sia effeminato il mondo, et disarmato il Cielo, nasce piu senza dubio dalla viltà de gli huomini, che hanno interpetrato la nostra religione secondo l'otio, et non secondo la virtù" (Maquiavelo 1531: 64-65). Hay que notar que en este pasaje Maquiavelo seguramente tiene en mente un ideal republicano que no solo comprende las virtudes militares, sino también las que llamaríamos hoy en día virtudes civiles, que se relacionan con ese amor a la libertad que menciona al inicio del texto. Por tanto, si nos atenemos a los términos de Maquiavelo, el pasaje es más complejo que la interpretación que de él hacen los autores antimaquiavélicos que aquí reseñamos, quienes concentran su atención exclusivamente en la capacidad del cristiano de tomar las armas y dejan de lado, por ejemplo, el tema de la libertad en las repúblicas antiguas.

7 El De nobilitate tuvo un notable éxito editorial en la Europa de su tiempo. Anglo cuenta diez ediciones diversas en latín y una traducción al inglés en el siglo XVI, sin contar la Opera Omnia. Además, la parte contra Maquiavelo fue incluida por Possevino en su Iudicium (Roma, 1592), que contó con otras dos ediciones en 1593 y 1594 (Anglo 2005:145). A pesar de ello, este historiador opina que los argumentos de Osorio "are rarely cited" (155), lo que achaca, en parte, al haberse limitado a un capítulo de una obra de Maquiavelo (Discursos, II, 2). Este hecho es, precisamente, el que resulta revelador para identificar la línea de pensamiento antimaquiaveliano específicamente ibérica, que Anglo no advierte. 
libros tratan De nobilitate civili y, según su traductor, Sánchez de Agüeros, fueron escritos durante su estancia en Bolonia, fruto de las conversaciones con Antonio Agustín, Sadoleto, Bembo y Contarini (Osorio 1954). Los tres libros siguientes tratan De nobilitate christiana, y en el último de ellos se encuentra la crítica a Maquiavelo. El motivo que, según declara Osorio, le impulsa a escribir la obra, es la actual decadencia de las ciudades, que achaca a la decadencia de la nobleza. Los lujos y refinamientos del estamento noble han provocado la decadencia de la sociedad civil en general, "pues, dado que todos vienen a ser imitadores de los nobles, nunca la plebe se hubiera infectado de tales costumbres, si el ejemplo de la nobleza no la hubiese llevado a exageraciones de lujo y a los abismos de la ambición" (Osorio 1954:167). No es casual que Osorio y Maquiavelo compartan este tipo de inquietudes: el tema de las causas de la decadencia del presente respecto a los tiempos pasados era, en el Renacimiento, un tópico sobre el cual solían discutir los humanistas. El tema tendría, además, una especial resonancia en España entre los autores que, a partir de finales del siglo XVI, empezarían a discurrir sobre las causas de la decadencia del imperio español.

Por tanto, para Osorio la nobleza juega un papel político esencial en el ámbito de la sociedad civil, pues es el espejo en el que se mira el resto de la sociedad (la plebe) y de su comportamiento depende la virtud de la república o, por el contrario, el florecimiento del vicio y la decadencia generalizada. En este sentido, el De nobilitate no consiste en un panegírico del estamento noble. Al contrario, parte de la constatación de que "cualquier mal parece originarse, como de su manantial, de los hombres de posición más alta, a quienes precisamente competía el refrenar, con la severidad de la ley, pero sobre todo con el ejemplo de su virtud, los brotes de insubordinación popular" (1954:167). Sin embargo, la carga crítica de la obra se detiene en la distinción, típica entre los humanistas de la época, entre una verdadera nobleza demostrada con 
hechos virtuosos y una falsa nobleza que se cree justificada por motivos de mero linaje y herencia. Partiendo de esta premisa, Osorio analiza la naturaleza de la nobleza, los motivos de su ejemplaridad y las cualidades de la verdadera nobleza, esto es, las virtudes que debe seguir todo noble, divididas en virtudes civiles y religiosas. Se puede advertir a simple vista las profundas implicaciones del tema de esta obra en una sociedad como la castellana, en la que la división estamental seguía en pleno vigor, y en la que el estamento noble, lejos de venir a menos, se convertía en aspiración de muchos.

Es en el tercer libro De nobilitate christiana donde Osorio se dedica, de manera explícita, a defender la compatibilidad de los valores cristianos y los valores militares, ambos propios de la nobleza. A este propósito sacará a colación la tesis de Maquiavelo sobre la incapacidad militar del cristiano. Frente al presupuesto maquiaveliano según el cual el ascenso del cristianismo provocó la decadencia de las repúblicas actuales, Osorio, como Sepúlveda y Ribadeneyra, siente de manera especial la necesidad de conciliar la ortodoxia cristiana con el estilo de vida militar y, en general, el catolicismo con los ideales guerreros.

En este sentido, parece probable que Osorio conociera la obra de Sepúlveda, si bien su estrategia a la hora de rebatir a Maquiavelo es distinta. El cordobés afirma la concordancia entre la doctrina de las virtudes de los filósofos clásicos (Aristóteles y los peripatéticos) y la cristiana, para demostrar que todos entienden lo mismo cuando hablan de virtudes. Esto le sirve para argumentar que la fortitudo clásica, fuente de las virtudes militares, se identifica con la fortaleza cristiana (Sepúlveda 1963: 180). A diferencia de Sepúlveda, Osorio no cree posible la conciliación entre el aristotelismo y la doctrina cristiana, si bien considera al griego "summus et doctissimus vir" (Bell 1928:534). No encontramos, por tanto, en Osorio, como sí en Sepúlveda, una filosofía de la razón y la 
ley natural sobre la cual fundar la obligatoriedad de las leyes cristianas. Hay, sin embargo, otros aspectos en los que sí se aprecian similitudes entre ambos autores ${ }^{8}$.

Osorio hace la primera referencia a Maquiavelo al abordar dos virtudes asociadas específicamente al oficio y los valores del soldado: la fortaleza y la magnanimidad -del mismo modo que Sepúlveda, si bien sin citar el nombre del italiano. Mientras da ejemplos de fortaleza cristiana, Osorio refiere un "impurus, quidam scriptor atque nefarius" que:

en los libros en los que escribió en italiano la historia de su ciudad y trató muchas cuestiones relativas a la República, no creyó necesario disimular su opinión en torno a nuestras santas creencias. La religión cristiana, escribe, ha destruido desde las raíces aquella grandeza de ánimo que resplandecía en los antiguos. La culpa de la ruina del Imperio romano, del decaimiento de las empresas gloriosas y famosas, de la decadencia de la misma virtud militar, debe imputarse, según él, a nuestra santísima religión dirigida hacia un Dios supremo y eterno. Sin embargo al final, para evitar ofender a los honestos en cualquier modo, él añade que de todo esto no se debe culpar a la religión en sí, sino a sus intérpretes,

8 Además del de Sepúlveda, Osorio también podría haber conocido otro de los primeros ataques a Maquiavelo fuera de Italia: la Apologia ad Carolum $V$ de Reginald Pole, compuesta en 1539. A pesar de que no fue publicada, es conocida la relación epistolar que Osorio mantuvo con el cardenal inglés, con quien pudo haber discutido las tesis de Maquiavelo. Curiosamente, tanto Sepúlveda como Osorio establecieron una relación epistolar con Pole, aunque nadie que yo sepa parece haber advertido pasajes de nociones y argumentos antimaquiavélicos a través de esta comunicación (se tiende a ver el antimaquiavelismo de Pole más como instrumento contra la monarquía de Enrique VIII que como un fin en sí mismo). Anglo también menciona un intercambio epistolar entre Roger Ascham y Reginald Pole sobre el De Nobilitate, después de que el primero se lo enviara al segundo en 1555 (2005: 143). 
que la han entendido mal, aunque luego no logra explicar en qué consista esta mala interpretación, que ha sido la causante de tantos males?.

La alusión a Discursos II, 2 es clara, a pesar de que Osorio no dé aquí el nombre de Maquiavelo. Sí lo hará más adelante, pues su crítica es mucho más extensa y detallada que la de Sepúlveda. Como puede apreciarse, la referencia toma en cuenta diversos aspectos de la tesis de Maquiavelo, además de la cuestión central (la religión cristiana vuelve a los hombres débiles e incompetentes para las virtudes militares) encontramos otros temas relacionados, como la apostilla maquiaveliana sobre los hombres que han interpretado la religión según el ocio y no según la virtud, sobre cuya sinceridad Osorio duda (al igual que muchos intérpretes actuales del florentino). Tras esta primera referencia general, Osorio advierte la necesidad de rebatir los argumentos de Maquiavelo por la rapidez con que sus ideas se propagan y se contagian: "late enim disseminatum est hoc malum, multosque funesta contagione graviter infecit” (1552: 201).

La refutación de las tesis de Maquiavelo por parte del humanista lusitano seguirá el hilo conductor de la definición de

9 Osorio muestra, en este pasaje, conocer también la Historia de Florencia (1532). La traducción del De Nobilitate Christiana es propia, a partir de la edición florentina: "in libris, in quibus \& suae ciuitatis historiam, \& multas quaestiones ad Reipublicam statum pertinentes Etrusco sermone complexus est, non putauit dissimulandum, quid de nostrorum sacrorum religione sentiret. Christianam religionem scribit illam magnitudinem animi, quae in antiquis elucebat, funditus sustulisse. Romani imperii ruinam, laudis \& gloriae labem, uirtutis etiam militaris interitum, huic sanctissimae summi \& aeterni dei religioni assignandum putat. Tum postremo, ut aliqua ex parteuitet offensionem bonorum, id inquit, non uitio religionis, sed interpretum, qui illam male intellexerunt accidisse: cum tamen non posset offendere, quae fuerit illa peruersa interpretatio, quae tantorum malorum causam praebuerit" (1552: 200). 
la verdadera virtud de la fortaleza, descrita de acuerdo con los parámetros cristianos en oposición a la falsa fortaleza, encarnada en la tesis de Maquiavelo -lo mismo hará Ribadeneyra años después. Así, en primer lugar Osorio argumenta que, dado que la fuerza para soportar agravios forma parte de la verdadera virtud de la fortaleza, nadie hace gala de mayor coraje y fortaleza que los mártires cristianos ${ }^{10}$. Si personajes como Anaxarco han sido laudados por no revelar, al ser torturados, los nombres de ciertos conjurados $-\mathrm{y}$ esto, nota Osorio, "el mismo Maquiavelo " lo juzgará digno de admirar ${ }^{11}-$, ¿no habrán de serlo más aquellos que, como los mártires cristianos, no se sacrifican por odio al tirano, sino por amor a Cristo? ¿Cómo va a volver timorato y débil una religión que arma de increíble resistencia incluso a los niños martirizados? La humildad no excluye el "animi magnitudo", dirá Osorio en el De Gloria (Bell 1928: 535). Los mártires cristianos han sido más numerosos y resolutos, aunque tal vez menos conocidos, que cualquier héroe pagano o gentil. “CCuál es esta perversión - pregunta a Maquiavelo-, que te lleva a admirar la sombra de virtud [de los gentiles] y tener en nada la virtud genuina?"12.

Sin embargo, Osorio es consciente de la posible objeción de Maquiavelo a su argumentación: el cristianismo vuelve los hombres fuertes para padecer el sufrimiento, pero débiles a

10 "Si fortitudines est comes inuicta patientia, quis nostrorum animum non admirabitur, cum uiderit ipsas etiam uirgines, pro Christi nomine, acerbissima supplicia, et omnes corporis cruciatus appetiuisse?” (1552: 201).

11 Se trata de la primera alusión explícita a Maquiavelo: "hos certe Machiauelus ipse, sic enim appellatur praeclarus scriptor, cum quo mihi res est, nullo modo contemnendos putabit" (1552: 201).

12 "Quae est ista mentis peruersitas, ut uirtutis umbram admireris, ueram uirtutem pro nihilo habendam putes?” (1552: 202-203). 
la hora de vengar las injurias recibidas ${ }^{13}$. De ese modo pasa a examinar, en segundo lugar, cuanto atañe a las virtudes militares en su relación con el cristianismo. Lo mismo hará Ribadeneyra casi cincuenta años después cuando, tras argumentar la fortaleza intrínseca al martirio cristiano, señala: "dirá por ventura Maquiavelo que la fortaleza de los mártires no es fortaleza política" (Ribadeneyra 1910: 573a), para enumerar después las virtudes de los soldados y guerreros cristianos.

"Debemos decir algo también de la virtud militar, que se encontraría, según éste [Maquiavelo], bien lejana de las costumbres y normas de vida de los cristianos" ${ }^{14}$. Osorio entiende que para Maquiavelo el único objeto de la virtud militar es el de alcanzar la gloria mundana, la cual, como enseñan los filósofos estoicos, debe ser despreciada. Si estos, a su vez, reivindican la fortaleza de ánimo, está claro entonces para el luso que fortaleza y gloria mundana nada tienen que ver. La verdadera fortaleza, por lo tanto, será la que se ve espoleada por ideales y valores diversos: "[Maquiavelo] razona como si solo el deseo de gloria pudiese incitar a la fortaleza, y no hubiera otros incentivos mayores y más vigorosos para el coraje, capaces de estimular noche y día los ánimos de los buenos para afrontar los peligros con decisión y voluntad; por ejemplo el amor por la patria, la defensa del honor personal, la reverencia por las leyes y por la religión: cosas que encuentran todas su más completa perfección en el cristianismo" 15 .

13 "Et se la religione nostra richiede, che tu habbi in te forteza, vuole che tu sia atto à patire, più che à fare una cosa forte" (Maquiavelo 1531: 65).

14 "Sequitur ut etiam de uirtute militari ali quid dicamus: quam iste Christianis moribus, et institutis longe alienam putat" (1552: 212).

15 "Hic autem sic argumentatur, quasi sola laudis cupiditas ad uirtutem acuat: et non alii multo potiores sint, uirtutis et industriae stimuli quibus bonorum animi, dies et noctes concitati, pericula libenter, et studiose suscipiant: nempe insignis in patriam beneuolentia, incredibilis ipsius dignitatis amor, egregia deinde legum, atque religionis observantia: quae 
Osorio adscribe valores propios del código de virtudes militares, como el amor por la patria o la defensa del propio honor, al código cristiano, hasta el punto de afirmar que es en la religión cristiana donde estos encuentran mayor perfección. De este modo, como argumentará después, la guerra hecha por la defensa de la patria y el honor no será ajena al espíritu cristiano, sino todo lo contrario.

Por otro lado, Osorio rechaza de lleno identificar la fortaleza con la fuerza o el arrojo. Como hiciera Sepúlveda, acude a la antigua doctrina aristotélica de la unión esencial entre las virtudes para argumentar que el hombre valeroso debe ser, por fuerza, también manso y modesto: "Si, como han enseñado los más doctos entre los hombres, todas las virtudes se encuentran unidas por un único vínculo, y si no es admisible entre ellas ningún contraste, es absurdo sostener que los dones de la modestia y la mansedumbre sean incompatibles con la más esplendida fortaleza [fortitudo], pues es imposible separarlas unas de otras. Por eso ningún hombre puede ser valeroso, si no es al mismo tiempo manso y moderado" 16 .

Si bien Osorio no da los nombres de los "hombres doctos" que sostienen esta unión esencial entre las virtudes, usa aquí un argumento que ya usara Sepúlveda en el Democrates primus: "todas las virtudes están entre sí de tal manera trabadas y ligadas que, si se quita una, necesariamente desaparecen las demás", opinión en la que concuerdan tanto los antiguos

quidem omnia sunt in Christianorum institutis perfectissima" (1552: 212-213).

16 "Si uero uirtutes omnes, ut etiam eruditissimi homines prodiderunt, uno coniuctionis uinculo continentur: nec ulla pugna inter illas esse potest: tantum abest, ut mansuetudinis, atque modestiae laus splendori fortitudinis aduersetur; ut etiam nullo modo à se inuicem diuelli, atque disiungi queant. Itaque nemo uir fortis esse potest: nisi idem sit mansuetus atque moderatus" (1552: 214). 
filósofos como teólogos como San Jerónimo y San Agustín (Sepúlveda 1963: 185-186). Así, al cristiano no pueden faltarle en ningún modo las virtudes propias del soldado, fortaleza y magnanimidad, pues faltando estas faltarían todas, lo que resulta inconcebible en un orden moral, civil y cosmológico cristiano. Más tarde encontraremos el argumento en el tratado de Ribadeneyra: "y así no puede haber verdadera y perfecta fortaleza sin paciencia, sufrimiento y mansedumbre"17. También llama la atención que acto seguido paragone la falsa fortaleza, suscitada no por el amor a la justicia sino por la cólera, con la ferocidad de las bestias salvajes (belluae). Sepúlveda había escrito en el Democrates primus que "los hombres injustos, que con muertes y robos turban el estado de la república y la paz de los buenos, son como lobos y demás animales dañinos" (1963: 166) ${ }^{18}$, y Ribadeneyra dirá que si la temeridad "fuese verdadera fortaleza y verdadera virtud, también, y aún mejor, la pondríamos en los leones" (1910: $567 \mathrm{~b})$.

Siguiendo la doctrina de la unión de las virtudes, Osorio argumenta que precisamente la fortaleza y la moderación, que parecen opuestas, están unidas de manera especial: "cum omnes uirtutes inter se conglutinatae sint; tum uel maxime animi moderatio, atque fortitudo" (1552: 215). Ahora bien, hay que saber cómo se da esta unión. Es un error en que incurren los seguidores de Maquiavelo pensar que, porque

17 Ribadeneyra incluye, entre los acicates para la verdadera fortaleza, los mismos que Osorio: "guardar y defender la ley de Dios, por amor de la patria, por hacer bien a muchos, por conservar y amplificar la santa religión" (1910: 570a).

18 Sepúlveda [1963, 166], si bien la metáfora cuenta con una larga tradición: contra los lobos el príncipe cristiano, pastor del rebaño de sus súbditos, debe hacer la guerra, y los soldados y gente de guerra están legitimados, por ello, a defender las ciudades contra los lobos, a la manera de mastines y guardias del rebaño. 
Cristo enseñó a perdonar las ofensas y poner la otra mejilla, los cristianos permanecerán impasibles ante una invasión militar: "cum ita mansueti sint, numquam impetum hostium a suis finibus depellent". Quien esto piensa, advierte Osorio, confunde los términos en que se despliegan las virtudes cristianas, pues: "otras son las personas, lugares, tiempos y causas que confluyen. Los mismos cristianos, que en privado reciben las ofensas y las injurias con moderación y paciencia, en el ámbito público se convierten en vehementes y acérrimos defensores de la seguridad pública y las libertades, especialmente cuando afecta a la dignidad de la religión. En ese caso juzgan la mansedumbre una vergüenza indigna, y la paciencia un crimen nefando" 19 .

Moisés y David constituyen ejemplos de esta doble actitud: siendo mansos y pacientes en soportar las ofensas privadas, no toleraron jamás la menor ofensa a la religión cristiana y no dudaron en responder con las armas (los mismos dos ejemplos encontramos en Ribadeneyra 1910: 570a). El mismo Jesucristo dio muestras de ello cuando echó con furia y violencia a los mercaderes del templo, quienes habían cometido sacrilegio al mancillar las sagradas ceremonias. De este modo coexisten, en el ánimo cristiano, las virtudes de la mansedumbre y la paciencia con la fortaleza de ánimo y el valor.

19 "Cum ita mansueti sint, numquam impetum hostium a suis finibus depellent, neque sceleri armis resistent; sed quemuis furorem beneficio compensabunt. Hoc qui dicit, minime expendit officiorum momenta: nec intelligit alia aliis personis, locis, temporibus, causis conuenire. Christiani ipsi, qui in priuatis offensionibus et iniuriis moderationem atque patientiam amplectuntur, iidem in publicis periculis acerrimi et uehementes publicae salutis, atque libertatis uindices existunt, praesertim ubi simul agitur dignitas religionis. Tunc enim mansuetudinem indignum flagitium, patientiam scelus nefarium arbitrantur" (1552: 216-217). 
Este es un punto central en la estrategia de Osorio para refutar no solo las tesis de Maquiavelo sobre la ineptitud militar del cristiano (el lusitano habla numerosas veces de la defensa de plazas y fortalezas frente a los enemigos de la religión), sino también las de los erasmistas sobre la incompatibilidad de la doctrina cristiana con el uso de la fuerza. Al respecto, las estrategias de Sepúlveda y Osorio difieren: la del primero reduce la ética cristiana en su totalidad a los Diez Mandamientos, lo que garantiza la salvación del alma del soldado que participa en las guerras de religión ${ }^{20}$. La del segundo, en cambio, distingue netamente los dos ámbitos en los que se desenvuelven las virtudes cristianas. El primero, a la vez que

20 De todos los mandamientos presentes en la Biblia, Sepúlveda distingue dos tipos: unos son necesarios y suficientes para vivir bien y conforme a la religión cristiana, a saber, los mandamientos del decálogo, “a los cuales se refieren todas las leyes naturales y en los cuales consiste toda la vida civil"; otros, en cambio, son provechosos para llevar una vida más perfecta, “a los cuales nos exhortan Cristo y los Apóstoles”, pero nadie está moralmente obligado a cumplirlos. Poner la otra mejilla es un acto de perfección cristiana propio del monje dedicado a la filosofía y la vida contemplativa, pero ningún cristiano está obligado a hacerlo: se trata más de un consejo que de un mandamiento, una amonestación para la mejor y más perfecta vida sin fuerza de ley obligatoria. De este modo, "defendernos de quien nos maltrata es obra de justicia; en cambio, sufrir la injuria sin resistir es perfección". Nadie está obligado a la perfección, pero sí, por ley natural, a la justicia: la guerra defensiva constituye, por tanto, una guerra justa que, como tal, ha sido querida por Dios; pues si Dios es la causa primera de toda naturaleza, y su voluntad es que se mantenga el orden natural, no hay decreto más justo ni natural que defenderse cada uno a sí mismo, a sus propiedades y a sus amigos. De todo esto concluye Sepúlveda que "la guerra no solamente no contradice la Ley divina cuando (...) tiene su origen en la fuente de la justicia, sino que se hace por autoridad de Dios", pues se hace siguiendo la naturaleza. De este modo, el filósofo cordobés pone las bases éticas sobre las que se levantará su justificación de un catolicismo militante y combativo (Sepúlveda 1963: 159-163). 
ensalzaba la moral del monje y su dedicación a la vida especulativa, lo convertía en la excepción y lo aislaba del resto de los oficios de la sociedad civil, todos ellos buenos, dignos y necesarios por igual (incluido el del soldado); el segundo concibe la ética del monje y la del soldado conviviendo dentro del mismo individuo; vigente la primera en el ámbito privado, la segunda solo se desplegaría en aquellos casos excepcionales en que se ofenda el honor propio ${ }^{21}$, la patria y, sobre todo, la religión; esto es, aquellos casos de guerra en nombre de un ideal nacional-católico que serían tan frecuentes en la España de Felipe II.

Otro aspecto de las tesis de Maquiavelo en Discursos II, 2 que Osorio toma en consideración es el de los sacrificios: "Él afirma que el sacrificio de víctimas y el holocausto de animales tenía en sí tal poder, que transformaba de golpe los hombres timoratos en audaces y feroces; por tanto nosotros, que no matamos víctimas, ni manchamos los altares con sangre de cuadrúpedos, ni examinamos vísceras, nos encontramos privados, por culpa de nuestra religión, de tamaño instrumento de virtud"22.

21 Osorio, sin embargo, no se ocupa de manera tan insistente como Sepúlveda del conflicto que se le plantea al militar en ámbito privado entre mansedumbre cristiana y defensa del honor, esto es, la cuestión del derecho a la venganza. En este sentido, puede ser significativo el hecho de que el cordobés escriba el Democrates primus, según afirma en el prólogo, tras disputar con jóvenes nobles dedicados a la guerra, con el propósito de convencerles de la compatibilidad entre milicia y religión (1963: 134).

22 "Tantan enim uim habuisse putat illam hostiarum caedem, atque pecudum stragem, ut repente ex timidis, feros et audaces efficeret. Nos itaque qui nec hostias caedimus, nec quadrupedum sanguine aras cruentamus, nec exta inspicimus, magnis ad uirtutem instrumentis hoc religionis incommodo priuari" (1552: 218). Maquiavelo, por su parte, había alabado el sacrificio antiguo afirmando que su "aspecto terrible", "lleno de sangre y ferocidad" y en el que "se mataban multitud de animales" volvía a los hombres igual de terribles: "Quivi non mancava la pompa, ne la 
Esta es una cuestión que Sepúlveda no toma en consideración en el Democrates primus. Osorio, en cambio, se detiene a discutirla detenidamente. Su primer argumento pasa por inferir, de manera irónica, que si los sacrificios vuelven a los hombres más valientes, entonces los carniceros y los verdugos deberían ser los soldados más valiosos: "con ese valor adquirido matando animales o con el suplicio de los condenados irrumpirían contra el enemigo, alejando de nosotros cualquier peligro"23. La referencia a los carniceros la encontramos también en el Tratado del príncipe cristiano, cuando observa Ribadeneyra que "si el ver derramar sangre de animales fuese bastante causa para engendrar en nosotros la fortaleza, no habría hombres más fuertes y valientes que los carniceros" (1910: 569a) ${ }^{24}$.

Osorio avanza contra la tesis de los sacrificios otro tipo de argumentos que Ribadeneyra dejará de lado: los sacrificios y ceremoniales paganos inducen más temor que no valor en quienes los presencian, pues para ellos cualquier fenómeno natural es un portento de origen divino inexplicable, razón por la cual viven en un estado de continua incertidumbre y temor. Frente a esto, los cristianos cuentan con la certeza de conocer el significado de los fenómenos naturales, de saber que Dios y los ángeles proveen las cosas terrenas y que hay vida eterna tras la muerte cristiana, lo que les da mayor valor (1552: 220).

magnificenza delle Cirimonie, ma visi aggiungeva, l'attione del sacrificio pieno di sangue, et di ferocia, ammazandovisi moltitudine di animali, il quale aspetto sendo terribile, rendeva gli huomini simili à lui" (Maquiavelo 1531: 64).

23 "Ut scilicet illa uirtute, quam aut sanguine pecudum, aut supplicio damnatorum adepti sunt, in hostes irruant, et à nobis omnia pericula propulsent" (1552: 218-219).

24 Anglo (2005: 152) señala la referencia a los carniceros en Vegecio y en Christine de Pisan, además del Arte de la guerra de Maquiavelo, que probablemente tenía Osorio a mano cuando escribía. 
No son los sacrificios, sino el amor y la caridad, los dos motivos más inspiradores a la hora de hacer frente a cualquier tipo de dificultad, y preparan al cristiano para sufrir la muerte a través de los más exquisitos tormentos que el cuerpo puede soportar: "nada puede incitar más fuertemente los ánimos para afrontar cualquier peligro mortal que el amor y la caridad"25. La misma muerte, que espanta a los ánimos más aguerridos, el cristiano la considera con indiferencia o incluso deseo. "Nada parece más grato y deseable a los cristianos -escribe-cuanto inmolar la propia vida entre tormentos corporales por la religión de Dios inmortal"26.

Esta descripción de una ética religiosa que, en el plano militar, da lugar a un desprecio por la vida y un deseo de muerte en el nombre de Dios propios de un mártir, la encontraremos, mucho más acentuada, en la obra de Ribadeneyra. En el Tratado del príncipe cristiano podemos leer que el cristiano "sabe que con la muerte no se remata, antes comienza la vida del que muere en justa guerra por defensa de la virtud" (1910: 569b). Se tratará de una constante en la obra de Ribadeneyra: en la Historia eclesiástica del cisma de Inglaterra (1588) ya había afirmado que el martirio de los católicos en Inglaterra "es beneficio tan grande y tan regalado del Señor, que nos obliga a todos los hijos desta mínima Compañía a reconocerle y servirle, y a desear seguir a nuestros hermanos, y dar la vida por él" (1595: 454). En esta obra, Ribadeneyra retrata a los que considera los tres grandes Maquiavelos ingleses del siglo XVI: Enrique VIII, su hija Isabel y Jacobo I. La acusación, para los tres, es la de haber puesto la religión al servicio de los intereses de la política. Así interpreta el jesuita el cisma de

25 "Nulla re magis incitari, an incendi animos ad omnia capitis pericula subenda, quam benevolentia, et caritate" (1552: 225-226).

26 "Nihil uidebatur Christianis aeque optabile, et expetendum, atque pro Dei immortalis religione, uitam in summis totius corporis cruciatibus amittere" (1552: 226). 
Inglaterra y deja clara la necesidad de acabar con tal muestra de ateísmo. Ciertamente, el contexto de la misión, el martirio y la inminente guerra contra la herejía inglesa exacerban el furor providencialista con el que Ribadeneyra llama a los suyos al combate y al sufrimiento: "En nuestra espiritual guerra y conquista, estamos ciertos de la victoria, no solamente porque sabemos, que si no morimos en ella, vencemos, y si morimos vencemos mucho más; pero porque somos ciertos, que ninguna crueldad de tiranos, ni malicia de herejes, ni furor de perseguidores, ni las mismas puertas, y todo el poder del infierno podrán jamás prevalecer contra aquella Iglesia, y Fe, que está fundada sobre la piedra y confesión de San Pedro, como nos lo dijo y prometió el Señor" (1595: 680).

De este modo, la idea de la promesa y el cumplimiento mesiánico de una providencia divina justifica e incluso obliga, en última instancia, tanto al sacrificio como a la guerra, como veremos ${ }^{27}$.

27 Vale la pena recordar, como ejemplo, que Ribadeneyra escribe en 1588 una exhortación a los soldados de la Gran Armada en la que afirma que su empresa es "justa y santa guerra" y que, aunque parezca ofensiva, es defensiva, pues en ella se defienden "nuestra sagrada religión y santísima fe católica romana" y "la reputación importantísima de nuestro Rey y Señor y de nuestra Nación", entre otros aspectos $(1945,1333)$. Un año después de la derrota el jesuita publicó un Tratado de la tribulación en el que, entre otras cosas, intentó dar respuesta al problema que, para el pensamiento providencialista, supuso tamaño desastre militar: ¿cómo es posible que Dios permita la derrota de quienes luchan en su nombre y bajo su mandato? Ribadenyra responde a esta pregunta interpretando la derrota como un castigo divino a los pecados de los españoles, entre ellos, el de la soberbia (1595: 776). Indirectamente, el monarca recibe también parte de la culpa, pues Felipe II habría emprendido dicha empresa anteponiendo su propio interés político a la misión de extender la religión cristiana y defender la "honra de Dios". Como advierte el jesuita, cuando se emprende guerra contra los herejes sin buscar en primer lugar la gloria de Dios "tenemos por principal lo accesorio, y lo accesorio por 


\section{Contra los pacifistas}

Con este argumento Osorio termina la refutación de Maquiavelo, si bien su reivindicación de un catolicismo violento y guerrero proseguirá con otro oponente en mente. Se excusa por haberse demorado tanto en un autor tan impío aludiendo a su relación con el tema que le interesa, el de la nobleza cristiana, pues es un autor que la ataca directamente. En lo que queda de la obra, el portugués se enfrentará al tipo de posiciones pacifistas de corte erasmista que ven la guerra y la destreza militar como opuestas a los mandamientos de Cristo. Por supuesto, Osorio recurre a pasajes del Antiguo Testamento que demuestran la maldición en que incurre quien no se entrega en cuerpo y alma en las guerras del Señor (1552: 229) y se enfrenta, como Sepúlveda, a la opinión de quienes retienen el Antiguo Testamento superado por el Nuevo. Osorio observa que las profecías y las viejas ceremonias del Antiguo Testamento, como la circuncisión, han quedado obsoletas, pero esto no puede en ningún modo compararse con la virtud militar, "que ha sido ordenada para la preservación del bien común" y pertenece al "estado civil" (civilem disciplinam). Son dos aspectos diversos que en ningún momento deben confundirse, pues todos los bienes de que disfrutamos en tiempo de paz son procurados, según el luso, por la marcialidad y la vigilancia de las armas, en las que se funda el Estado ${ }^{28}$.

principal", por lo que "no es maravilla que permita el Señor que se pierdan las jornadas" (1595: 778).

28 "Hoc autem de bellica uirtute existimari non potest: cum non in ceremoniarum rationem cadat: sed causa publica salutis custodiendae exculta sit, et ad ciuilem disciplinam pertineat. Confundere autem ea quae sunt secernenda, aut extremae dementiae est; aut summae temeritatis argumentum. Cum uero reipublicam status stabiliri non possit, nisi armorum praesidio fulciatur: siquidem omnes artes pacis sunt in tutela militaris 
Cristo, prosigue Osorio, no quería que el estado civil fuera superado, sino establecido y confirmado. Así como el magistrado, armado con la autoridad de las leyes, puede suprimir a los indeseables y mantener la seguridad dentro del Estado; de la misma manera, el soldado, armado con la espada, puede repeler el peligro exterior (1552: 231). Estos argumentos, junto con la cita de pasajes del Nuevo Testamento, como Lucas 3:14, en el que se refieren las palabras de Juan el Bautista a los soldados ("contentaos con vuestro salario"), son lugares comunes de la tradición cristiana bélico-apologética, tal como ha señalado Roland Bainton (1960: 53-65).

Otro argumento antipacifista de Osorio defiende que la guerra es consecuencia de la maldad intrínseca a la naturaleza humana: "nada más deseable para el hombre cristiano que todo el género humano se alejara de la locura y el pecado" -observa el humanista luso-, pero visto que no es así y que en lugar de la continencia reina el desenfreno; y en lugar de la justicia, la fuerza, entonces es necesario contrarrestar al enemigo con armas y poder, y reprimir el ultraje a nuestros ciudadanos con la espada (1522: 231). Los pacifistas podrían observar que esto es contrario a la caridad cristiana, a lo que el portugués replica de nuevo con la distinción entre moralidad pública y privada: Cristo ha ordenado no tomar venganza de las injurias privadas y profesar una singular paciencia de ánimo, "pero cuando la seguridad común o la dignidad de la religión se ven amenazadas, entonces se hace necesario tener un estómago invencible contra la maldad y la bellaquería"29. La paz cris-

disciplinae, qui militiam tollit, is rempublicam funditus euertit" (1552: 230). De manera parecida, Sepúlveda justificaba la guerra como preservadora del orden y la paz.

29 "Praecipit Christus ne illatam injuriam ulciscamur. Est quidem perfectae cumulataeque uirtutis, ubi nobis iniuriae priuatim inferuntur: miram et singularem animi patientiam ostendere: ubi uero, aut communis salus, 
tiana no puede subsistir en el ocio y el reposo; es necesario luchar por ella empleando la santa violencia de las armas.

\section{Imperialismo católico}

El resto del De nobilitate chrisitana continúa con la enumeración de los caballeros cristianos más famosos del pasado (tarea a la que también se había dedicado Sepúlveda y que ocupará, más adelante, a Ribadeneyra): hebreos como Gideón, Abraham y Josué; cristianos como Constantino, Teodosio, Carlo Martello, Carlo Magno y Godofredo; y, finalmente, los "guerreros ibéricos": Fernando de Aragón, Alfonso I y Manuel I de Portugal, junto con el rey Juan III, hermano del príncipe Luíz (a quien Osorio dedica el De nobilitate). Lógicamente, dada la nacionalidad de Osorio, hay en esta lista una mayor presencia de nobles portugueses en comparación con los otros dos autores. Sin embargo, no parece que Osorio haga demasiadas distinciones en cuanto a la nobleza cristiana portuguesa o española. Bell ha hablado de un imperialismo católico de corte más bien portugués. En el De nobilitate christiana Osorio se congratula por los portentosos avances del cristianismo en el orbe de mano de los portugueses (lusitani), quienes han atravesado el globo de norte a sur y de este a oeste. Etiopía ha sido conquistada, las ciudades de Arabia y Asia sometidas, India dominada, el poder turco derrocado. Los "moros", los persas, los turcos y los árabes no han sido vencidos por la habilidad, el valor o el poder de la guerra, sino por la piedad y la religión (1552: 240). Sin embargo, también habla de la extensión de Hispania por África, América y Europa de la mano de Fernando el Católico, lo que

aut religionis dignitas agitur: inuictum robur contra furorem, atque scelus assumere" (1552: 231-232). 
para el luso obedece a la voluntad de Cristo. Elías de Tejada, por su parte, aporta citas para argumentar cómo Osorio no hace demasiadas diferencias entre portugués y español, y llama a veces españoles a los reyes de Portugal, y habla de un "reino del occidente peninsular" y de una "Hispania nostra" (1945: 380).

Como se ha dicho, Osorio defendió las pretensiones de Felipe II al trono portugués contra las aspiraciones de Antonio, Prior de Crato, a cuya casa el humanista luso había estado estrechamente vinculado. Osorio llega a escribir una carta $D e-$ fensio sui nominis (1580, contenida en la Opera Omnia de 1592) en la que, al defender los derechos del monarca español a la corona, deja ver -según Tejada - su concepción de un imperio católico transnacional, cuyo centro debe encontrarse en la península ibérica. La unión con Castilla supone el fin de las discordias entre los reinos españoles bajo un único rey legítimo heredero de los tres grandes reinos peninsulares. Osorio no entra en la cuestión de los títulos legalistas de Felipe, remitiendo al parecer de los jurisconsultos - “de iure non disputo", declarará. "El argumento de mayor notoriedad -apunta Tejada- es que el Rey de Castilla es quien posiblemente traerá, al ceñir la corona de las cinco quinas, un más grande beneficio al pueblo portugués, incomparablemente mayor que el que puedan brindarle sus rivales" (1945: 384). Osorio entiende que con esta unión la fe cristiana lograría extenderse a toda la humanidad, por la palabra o por el acero, pues la concordia entre los cristianos permitiría la extinción de mahometanos y herejes para llevar finalmente a término el objetivo final de la unidad, que es la extensión universal de la fe de Cristo. De este modo, Osorio se adhiere a la concepción neoimperial cuya formulación debemos, en gran parte, a Sepúlveda, y que tomará forma plena en la monarquía de Felipe II, esto es, la formulación de un "imperio de por sî", sustentado no en los títulos imperiales, sino en el poder de facto que ostenta el rey español frente al 
escaso poder aglutinador del pretendiente portugués al trono (Fernández Albadalejo 1993). Este poder fáctico, por su parte, se justifica a nivel teológico político mediante el ideal de la cruzada para la extensión mundial del catolicismo, que la monarquía española convertirá en su bandera. De hecho, el monarca con frecuencia se presentará, y será concebido, como el representante de Dios en la tierra, llamado a cumplir la misión, asignada por la Providencia, de extender el cristianismo en todo el orbe. El notorio juicio de Tommaso Campanella en La Monarchia di Spagna (1600), según el cual esta se funda en la oculta providencia de Dios más que en la prudencia, era compartido por buena parte de los súbditos del monarca. El mismo Felipe II, a la hora de justificar sus decisiones políticas, se presenta como ejecutor de una voluntad divina y muestra muchas características comunes a las visiones providenciales propias de su época: cumplimiento de profecías de un cambio global; presentación del imperio del rey como algo nuevo en la historia mundial; y el supuesto de que el "mesías" podía discernir el propósito de Dios para el mundo y perseguir las políticas adecuadas para alcanzarlo. Estas características han llevado a autores como Geoffrey Parker a afirmar, no sin polémica, la existencia de un "imperialismo mesiánico" en el programa político de Felipe II (2013: 240), dentro del cual la estrategia del antimaquiavelismo ibérico cobra pleno sentido.

La argumentación contra las tesis de Maquiavelo en Discursos II, 2 y la consecuente reivindicación de un catolicismo que, más que permitir, obliga al cristiano a tomar las armas cuando están en peligro "la dignidad de la patria o de la religión”, se encuentra por tanto estrechamente relacionada con esta concepción de un "imperialismo cristiano hispánico" de corte providencialista, que también encuentra plena reivindicación en Ribadeneyra. 


\section{Sobre la decadencia de Roma}

Si bien no hereda de su padre el Sacro Imperio Romano Germánico, Felipe II es el protagonista de una retórica política que propone y busca legitimar un "imperio de por sí" que le sea comparable, si no en cuanto a títulos, sí en cuanto a extensión y poder efectivo. Como hemos visto, Osorio es favorable a la aceptación de este nuevo tipo de imperio que, en sus empresas transatlánticas, había llegado a realizar una proeza inédita: descubrir un nuevo mundo desconocido incluso para los grandes imperios del pasado, los cuales constituían, frecuentemente, la vara de medir de las nuevas monarquías $^{30}$. La monarquía española podía, por tanto, presentarse como superior al Imperio romano y elegida por el Dios de los cristianos. No es de extrañar, por tanto, que la decadencia del Imperio romano constituya un tema de discusión sobre el cual proyectar temores, reservas y esperanzas que muchos albergaban para el Imperio ibérico. El tema resulta mucho más acuciante para aquellos autores que, como Osorio y Ribadeneyra, se escandalizaban de la responsabilidad que Maquiavelo atribuía a la religión cristiana en la debacle romana.

Adriano Prosperi ha señalado que este debate se desarrollaba, de manera más vigorosa, en otros centros de producción ideológica y propagandística de la Contrarreforma, como por ejemplo Roma, mientras que la cuestión de la conciliación entre cristianismo y milicia, "con preferencia de las

30 Ribadeneyra, por ejemplo, afirma que "las cosas extrañas y que exceden el curso común (...) que han hecho los portugueses en las Indias Orientales por mar y por tierra, y los Castellanos en las Occidentales, en Italia, Germania y Flandes en nuestros días, son tantas y tan hazañosas, que ningunas de las que leemos en las historias griegas y latinas (por más que los escritores las levanten con elegancia y ornato de palabras) se pueden con ellas igualar, o a lo menos a ellas preferir" (1910: 575a). 
virtudes bélicas", era la que se desarrollaba de manera prevalente en España, a través de obras como las que nos ocupan aquí (1994: 59-69). Sin embargo, no se trata de dos temas independientes, por lo que su presencia en las obras de Osorio y Ribadenerya resulta insoslayable.

Maquiavelo, como vimos, había afirmado que la religión cristiana, interpretada según el ocio, había vuelto a los hombres afeminados y dejado el mundo débil, pasto de los "hombres malvados" (uomini scelerati) ${ }^{31}$. Contra la acusación al cristianismo de debilitar el mundo, Osorio advierte que hay un proceso natural de ascenso, esplendor y decadencia que atañe a cualquier imperio, como ha sucedido a persas, griegos y romanos: "Mediocria facile se sustentant, summa vero sua mole dissipantur et ruunt" (1552: 205). Lo raro, en realidad, no es la decadencia, sino la larga duración de un Estado, por lo que habría que preguntarse por el caso de Esparta, cuyo gobierno y orden social perduró mucho más que el de Atenas. Mientras más grande sea la estructura, más fácilmente puede caer, por lo que el caso del Imperio romano resulta también excepcional, debido a la gloria y el dominio establecido por Roma ${ }^{32}$.

31 En el segundo libro del Arte de la guerra, el florentino también trata la cuestión de las causas de la decadencia de Roma, que no viene imputada a la religión. Sí dice Maquiavelo que las antiguas virtudes, sofocadas por Roma, no han vuelto a renacer "perché il modo del vivere d'oggi, rispetto alla cristiana religione, non impone quella necessità al difendersi, che anticamente era" (Maquiavelo [1992, 216]).

32 Por desgracia, Osorio no explica cómo conciliar esta interpretación del desarrollo "natural" de los estados, que recuerda la doctrina clásica de la anacyclosis de la que el mismo Maquiavelo se hace eco en Discursos II, 5, con la interpretación providencial de la historia propia del catolicismo. Una referencia a sus raíces aristotélicas y su significado en el pensamiento político de Osorio en Bigalli (1995: 113 y siguientes). 
Ante esta evidencia, Osorio se pregunta cómo los seguidores de Maquiavelo pueden lamentar la decadencia y caída de Roma, "como si hubiera debido ser perpetua, de no ser por el impedimento que supuso la religión de Cristo"33. La realidad es que la sobriedad, el vigor y la fortaleza de los antiguos romanos ya habían desaparecido mucho antes del ascenso del cristianismo, debido a la disipación de las costumbres: lujo, avaricia, disensiones internas y debilidad de ánimo habían reemplazado los antiguos valores. Cuando un número cada vez mayor de personas prefiere el placer y la riqueza personal antes que el beneficio público; cuando las finanzas del Estado son administradas de manera corrupta; cuando prevalece el desorden económico y social, entonces un imperio ha llegado a su fin (1522: 206-207).

Este argumento lo encontramos también en el Tratado del príncipe cristiano, que habla en su capítulo treinta y nueve de "Que la regalada educación es causa que los hombres no sean fuertes y valientes" (1910: 575a). Sin conceder la culpa atribuida a la religión cristiana por parte de Maquiavelo, Ribadeneyra sostiene que en esto tiene razón el florentino (como implícitamente hace Osorio), pues una educación rígida y disciplinada es causa de fortaleza en un Estado, mientras que el lujo y la prosperidad tienden a ablandar los ánimos y quitar el vigor a los ciudadanos.

Como hemos visto, muchas son las conexiones entre Sepúlveda, Osorio y Ribadeneyra. Las semejanzas entre algunas argumentaciones de estos dos últimos hacen pensar que Ribadeneyra, probablemente, tuviera el De nobilitate christiana a mano cuando escribía su tratado. El humanista luso debió ser muy conocido por los jesuitas, no solo por la fama de sus obras, sino también por su relación con la

33 "Quasi futura esset immortalis, ni Christi religio impedimento fuisset" (1552: 205). 
Compañía. Como se ha mencionado, en 1525 Osorio conoció personalmente a Ignacio de Loyola en París y trabó estrecha amistad con Pedro Fabro. Como curiosidad, resulta significativo que un artículo de 1820 aparecido en el diario El Censor sobre la publicación del Príncipe en España dijera de Osorio "que dejó sus bienes a la compañía", acusándole además de criticar a Maquiavelo en el De Nobilitate sin haberlo leído, "a instigación del dominico Politi (referencia a Ambrogio Catarino Politi, autor en 1551 de un opúsculo sobre Quam esecrandi Macchiavelli discursus et institutio principis) y de los jesuitas" (108). Sin parecer esto muy probable, hace patente las similitudes entre la crítica de Osorio a Maquiavelo y la de jesuitas posteriores, especialmente castellanos. De este modo, la obra de Osorio se puede leer como un espacio de tránsito y creación de imágenes, argumentos y motivos antimaquiavélicos que contecta el argumentario de Sepúlveda con parte de la cultura político-religiosa ibérica desde finales del siglo XVI hasta mediados del XVII. Posteriormente, Ribadeneyra retomará estos motivos para incorporarlos en su Tratado del príncipe cristiano a una crítica más general, desde la cual construirá una razón "que de la religión hace Estado" y que inaugurará una línea de pensamiento político que culminará con la publicación, en 1648, de Idea de un príncipe cristiano de Diego de Saavedra Fajardo (Iñurritegui 1998, 41-42). El providencialismo y el carácter militante de esta doctrina constituirán la principal arma de un arsenal que, dentro de la verdadera razón de Estado cristiana, permitirá al príncipe acudir a los preceptos morales católicos para legitimar la expansión política mediante la guerra. Como hemos visto, la obra de Osorio constituye uno de los pilares sobre los cuales se asienta dicha doctrina. 


\section{Bibliografía}

ANGLO, Sydney

2005 Machiavelli - The First Century. Studies in Enthusiasm, Hostility, and Irrelevance. Nueva York: Oxford University Press.

BAINTON, Roland H.

1960 Christian Attitudes toward War and Peace. A Historical Survey and Critical Re-evaluation. New York, Nashville: Abingdon Press.

BELL, Aubrey F. G.

1928 "The humanist Jeronymo de Osorio". Revue Hispanique, 73, pp. 525-556.

BIGALLI, Davide

1995 "Jerónimo Osorio: tra crisi dell'erasmismo politico ed emergere della ragion di stato". En BALDINI, Enzo A. (editor). Aristotelismo político e ragion di Stato. Florencia: Leo S. Olschki editore, pp. 103-114.

1990

"Isole di dottrina: il dialogo 'De Gloria' di Jerónimo Osorio". En BIGALLI, Davide y Guido CANZIANI (editores). Il diálogo filosófico nel '500 europeo. Milán: FrancoAngeli.

BIRELEY, Robert

The Counter-Reformation Prince. Anti-Machiavellianism or Catholic Statecraft in Early Modern Europe. Chapel Hill: The University of North Carolina Press.

BJAÏ, Denis

2013

"La répresentation de l'Orient dans les Essais de Montaigne". En CLASSEN, Albrecht (editor). East meets West in the Middle Ages and Early Modern Times. Transcultural Experiences in the Premodern World. Berlin: De Gruyter, pp. 649-666. 
CASTRO, Nair de Nazaré

1994 O Príncipe Ideal no Século XVI e a Obra de D. Jerónimo Osório. Coímbra: Instituto Nacional de Investigação Científica.

COROLEU, Alejandro

1992 “Il 'Democrates primus’ di Juan Ginés de Sepúlveda: una nuova prima condanna contro il Machiavelli. Il pensiero politico, XXV, pp. 263-268.

DÍAZ, Gonzalo

1998 Hombres y documentos de la filosofía española, vol. VI. Madrid: CSIC, Centro de Estudios Históricos.

FERNÁNDEZ ALBADALEJO, Pablo

1993 "'Imperio de por sí': la reformulación del poder universal en la temprana edad moderna". En Fragmentos de monarquí. Trabajos de historia politica. Madrid: Alianza.

FORTE, Juan Manuel y Pablo LÓPEZ (editores)

2008 Maquiavelo y España: Maquiavelismo y antimaquiavelismo en la cultura española de los siglos XVI y XVII. Madrid: Biblioteca Nueva.

HOWARD, Keith D.

2014 The Reception of Machiavelli in Early Modern Spain. Suffolk: Tamesis.

IÑURITEGUI, José María

1998 La gracia y la república. El lenguaje politico de la teología católica y el 'Príncipe Cristiano' de Pedro de Ribadeneyra. Madrid: UNED.

MAQUIAVELO, Nicolás

1992

Dell'arte della guerra. En ANSELMI, Gian Mario y Carlo VAROTTI (editores). Le grandi opere politiche, vol I. Turín: Bollati Boringhieri. 
Discorsi di Niccolò Machiavelli cittadino, et segretario fiorentino sopra la prima Deca di Tito Livio a' Zanobi Buondelmonti, et a' Cosimo Rucellai. Florencia: Bernardo Giunta.

MÉCHOULAN, Henry

1997 "Le dieu des antimachiaveliens espagnols du siecle d'or". En DIERKENS, Alain (editor). L'antimachiavelisme, de la Renaissance aux Lumières. Bruselas: Editions de l'Université de Bruxelles, pp. 85-95.

1994 "La raison d'Etat dans la pensée espagnole au siècle d'Or, 1550-1650”. En ZARKA, Yves Charles (editor). Raison et déraison d'Etat. Théoriciens et théories de la raison d'Etat aux XVI et XVII siècles. Paris: Presses Universitaires de France, pp. 245-263.

MONTAIGNE, Michel de

1837 Oeuvres de Michel de Montaigne [1595]. Paris: A. Desrez.

OSORIO, Jerónimo de

1957 "La nobleza civil”. Revista Hidalguí. Volumen V, números 21, 25, 27 y volumen VI, número 31.

1552

Hieronymi Osorii Lusitani De Nobilitate Civili Libri II. Eiusdem de Nobilitate Christiana Libri III. Florencia: Laurentium Torrentinum.

PARKER, Goffrey

2013 Felipe II. La biografía definitiva. Barcelona: Planeta.

118 PROCACCI, Giuliano

1995 Machiavelli nella cultura europea dell'Età Moderna. RomaBari: Laterza.

1965 Studi sulla fortuna del Machiavelli. Roma: Istituto Storico per l'Età Moderna e Contemporanea. 
PROSPERI, Adriano

1994 "I cristiani e la guerra: una controversia fra '500 e "700". Rivista di Storia e Letteratura Religiosa. volumen XXX, número 1, pp. 57-83.

PUIGDOMÈNECH, Helena

1988 Maquiavelo en España. Presencia de sus obras en los siglos XVI y XVII. Madrid: Fundación Universitaria Española.

RIBADENEYRA, Pedro de

1945 Exhortación para los soldados y capitanes que van a esta jornada de Inglaterra, en nombre de su Capitán General. En REY, Eusebio (editor). Historias de la Contrarreforma. Madrid: Editorial Católica.

$1910 \quad$ Tratado de la religión y virtudes que debe tener el principe cristiano para gobernar y conservar sus estados, contra lo que Nicolás Maquiavelo y los políticos deste tiempo enseñan. En DE LA FUENTE, Vicente (editor). Obras escogidas del padre Pedro de Rivadeneira. BAE. Volumen 60. Madrid: Imprenta de los Sucesores de Hernando.

1595 Las Obras Del P. Pedro De Ribadeneyra De La Compañia De Iesus. Madrid: en casa de la viuda de Pedro Madrigal, a costa de Juan de Montoya.

SEPÚLVEDA, Juan Ginés de

1963 Democrates primus. De la compatibilidad entre la miliciay la religión [1535]. En LOSADA, Ángel (editor y traductor). Tratados políticos. Madrid: Instituto de Estudios Políticos.

TEJADA, Francisco Elías de

1945 "Las doctrinas políticas de Jerónimo Osorio". Anuario de Historia del Derecho Español, 16, pp. 341-388. 